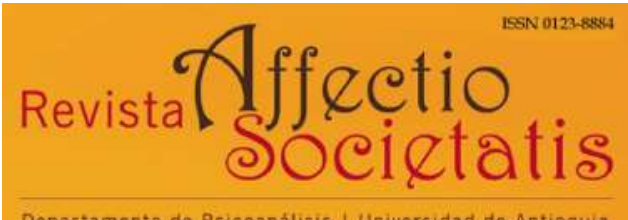

Departamento de Psicoanálisis / Universidad de Antioquia

Revista Affectio Societatis

Departamento de Psicoanálisis

Universidad de Antioquia

revistaaffectiosocietatis@udea.edu.co

ISSN (versión electrónica): 0123-8884

Colombia

Jacqueline de Oliveira Moreira, Diego Fernando Bolaños, Bianca Ferreira Rodrigues Nombre propio, nombre substituto y apodos: la adolescencia entre el yo y el Otro Revista Affectio Societatis, Vol. 17, N. ${ }^{\circ} 33$, julio-diciembre de 2020 Art. \#6 (pp. 133-155)

Departamento de Psicoanálisis, Universidad de Antioquia Medellín, Colombia 


\title{
NOMBRE PROPIO, NOMBRE SUBSTITUTO Y APODOS: LA ADOLESCENCIA Y SUS EXPERIENCIAS ${ }^{1}$
}

\author{
Jacqueline de Oliveira Moreira ${ }^{2}$ \\ Pontifícia Universidad Católica de Minas Gerais, Brasil. \\ jackdrawin@yahoo.com.br \\ https://orcid.org/0000-0003-0901-4217 \\ Diego Fernando Bolaños ${ }^{3}$ \\ Universidad Santiago de Cali, Colombia. \\ diferbol_21@ hotmail.com \\ https://orcid.org/0000-0002-6629-4705 \\ Bianca Ferreira Rodrigues ${ }^{4}$ \\ Pontifícia Universidad Católica de Minas Gerais, Brasil \\ biancaferreira025@gmail.com \\ https://orcid.org/0000-0002-7877-6808
}

DOI: 10.17533/udea.affs.v17n33a06

1 El artículo se deriva del estudio, que bajo la modalidad investigación-intervención de orientación clínica, se denominó constitución de subjetividad en adolescentes integrantes de agrupaciones juveniles de ciudad -AJC- en Mar del Plata (Argentina) y Cali (Colombia) y que derivó en la tesis doctoral titulada "Respiramos el mismo aire, pero somos diferentes" defendida en el año 2017 en el marco del doctorado latinoamericano en educación, políticas públicas y profesión docente de la Universidad Federal de Minas Gerais (UFMG) Brasil. Dos de los autores, Moreira y Bolaños, tienen relación directa con el producto, la primera fue jurado de la tesis y el segundo quien la elaboró.

2 Doctora en Psicología Clínica de la Pontificia Universidad Católica de São Paulo (PUC-SP). Magister en Filosofía de la Universidad Federal de Minas Gerais. Profesora del Programa de Post-Graduación en Psicología de la Pontificia Universidad Católica de Minas Gerais. Bolsista Productividad CNPq. Psicoanalista.

3 Doctor y postdoctor en Educación de la Universidad Federal de Minas Gerais, Belo Horizonte. Docente de la Facultad de Salud de la Universidad Santiago de Cali, Colombia. Psicoanalista.

4 Doctoranda en Psicología de la Pontificia Universidad Católica de Minas Gerais. Magíster y graduada en Psicología de la Universidad Federal de São João del-Rei (UFSJ). Bolsista CAPES. Psicoanalista. 


\section{NOMBRE PROPIO, NOMBRE SUBSTITUTO Y APODOS: LA ADOLESCENCIA Y SUS EXPERIENCIAS}

\section{Resumen}

Con el objetivo de pensar la función del nombre como marca singular articulado con el tema de la identificación en el Psicoanálisis, este texto analiza la adolescencia a partir de las transformaciones del cuerpo y del deseo de ser libre que llevan a referir el encuentro con el otro como asuntos decisivos en el proceso de constitución de sí. La importancia que toma el nombre propio, con su particularidad de ser histórico, inscribirse en la cultura y estar atravesado por los deseos inconscientes al igual que la identificación son puntos claves en la discusión que ubica las creaciones de nombres como prácticas comunes en la adolescencia en las que el usos de apodos y seudónimos funciona como renombramiento, sustitución, desplazamiento y cambios de nombres inicialmente asignados.

Palabras Clave: Identificación; Nominación - Renombramiento; Adolescencia; Sustitución de nombre

\section{PROPER NAME, SUBSTITUTE NAME, AND NICKNAMES: ADOLESCENCE AND ITS EXPERIENCES}

\section{Abstract}

In order to think about the function of the name as a singular mark articulated with the question of identification in psychoanalysis, this paper analyzes adolescence from the transformations of the body and the desire to be free which lead to consider the encounter with the other as decisive issues in the process of constituting oneself. The importance that the proper name takes, with its particularity of being historical, to be inscribed in the culture and to be crossed by unconscious desires, as well as identification, are key points in the discussion that locates the creations of names as common practices in adolescence in which the use of nicknames and pseudonyms works as renaming, substitution, displacements, and change of names initially assigned.

Keywords: identification, naming - renaming, adolescence, name substitution 


\section{NOM PROPRE, NOM DE REMPLACEMENT ET SURNOMS : L'ADOLESCENCE ET SES EXPÉRIENCES}

\section{Résumé}

Dans le but de réfléchir sur la fonction du nom comme marque singulière articulé avec le thème de l'identification en psychanalyse, ce texte analyse l'adolescence à partir des transformations du corps et du désir d'être libre qui conduisent à considérer la rencontre avec l'autre comme des enjeux décisifs dans le processus de constitution de soi. L'importance que prend le nom propre, avec sa particularité d'être historique, de s'inscrire dans la culture et d'être traversé par les désirs inconscients, ainsi que l'identification, sont des points clés dans la discussion qui place les créations de noms propres comme des pratiques courantes à l'adolescence dans lesquelles l'utilisation de surnoms et de pseudonymes fonctionne comme renommage, déplacement et changement des noms initialement attribués.

Mots clés : identification, nomination - renommage, adolescence, remplacement du nom.

\section{NOME PRÓPRIO, NOME SUBSTITUTO E APELIDOS: A ADOLESCÊNCIA E SUAS EXPERIÊNCIAS}

\section{Resumo}

Com o objetivo de pensar a função do nome como marca singular articulado com o tema da identificação em Psicanálise, este texto analisa a adolescência a partir das transformações do corpo e do desejo de ser livre, as quais levam a referir o encontro com o outro em quanto que questões decisivas no processo de constituição de si mesmo. A importância que o nome próprio adquire, com sua particularidade de ser histórico, de se inscrever na cultura e de estar atravessado por desejos inconscientes, bem como a identificação, são pontos-chave na discussão que situa as criações de nomes como práticas comuns na adolescência, nas quais o uso de apelidos e pseudônimos funcionam como renomeação, substituição, deslocamento e mudança de nomes dados inicialmente.

Palavras-chave: Identificação; Nomeação - Renomeação; Adolescência; Substituição de nome

Recibido: 29/08/2019 • Aprobado: 05/04/2020 
Para el psicoanálisis, la experiencia de la adolescencia convoca un importante e intenso trabajo psíquico, subjetivo y relacional. Varios aspectos deben ser considerados cuando pretendemos pensar al adolescente; particularmente en este texto se resaltan dos: las transformaciones del cuerpo, comunes en esta fase, y el deseo de ser libre.

Según Lacadée (2007), el adolescente quiere estar fuera, con los otros, quiere vivir con los otros, ser libre. El encuentro de estas dos fuerzas, a saber, los cambios en el cuerpo y el deseo de ser libre, puede producir en el adolescente una búsqueda idealizada por una "verdadera vida", para usar la expresión del poeta Arthur Rimbaud, presentada por Lacadée (2007). Esta idea de una "verdadera vida" se articula con la posibilidad de muerte de la "falsa vida" ofrecida por los padres, la muerte de una vida infantil y la apertura para la creación de una vida nueva. Las transformaciones del cuerpo presentan un papel significativo en ese proceso, exigiendo, pues, una nueva configuración narcisista de sí, un recrearse, principalmente, a los ojos de los otros. Pero, ¿el adolescente está listo?, ¿posee herramientas para producir una nueva imagen de sí?

Consideramos que en el psicoanálisis el tema de la identificación y, por consiguiente, del encuentro con el otro, es decisivo en el proceso de construcción de sí, no pudiéndose olvidar la importancia del nombre propio y de las creaciones de nombre que aparecen en la adolescencia (apodos, renombramientos, cambios de nombre) en este proceso. De igual forma, cuando es posible de traducción, es necesario que se respete el nombre propio. Al recibir un nombre, el niño recibe la marca que lo diferencia de todas las cosas y personas en el mundo. Esta marca tiene la historia familiar, por lo tanto, un nombre siempre es histórico, se inscribe en la cultura y es atravesado por los deseos inconscientes. Podemos afirmar que la nominación, la inscripción de un nombre propio, tiene la función de dar consistencia al sujeto.

Frente a lo anterior, este texto tiene como objetivo pensar la función del nombre, de los apodos y de los renombramientos desde la perspectiva del psicoanálisis freudiano-lacaniano. Para ello se privilegia el concepto de identificación, que remite al proceso de constitución psíquica dada en el seno de la relación con el otro y 
con la cultura, y en la cual la nominación posee un papel central. Es en esa intercepción entre individuo y sociedad que este trabajo se sitúa reafirmando la concepción biopsicosocial freudiana (Rosa, 2004, pág. 333).

Además, los fragmentos de casos tomados de Bolaños (2017) nos permitirán pensar en el uso de apodos o renombramientos entre los adolescentes para establecerse con una nueva inscripción en el mundo, lo cual viene a ser el tema central de la tesis de Diego Fernando Bolaños, titulada "Respiramos el mismo aire; pero somos diferentes". Constitución de subjetividad en adolescentes integrantes de agrupaciones juveniles de ciudad en Mar del Plata (Argentina) y Cali (Colombia). Con el objetivo de recortar el problema de constitución psíquica del adolescente, Bolaños discutió el tema de los apodos, de los nuevos nombres que algunos adolescentes crean para sí y cómo esto se relaciona con la subjetividad de cada uno.

Se inicia este recorrido hablando del proceso por el cual cada recién nacido tiene su cuerpo biológico atravesado por el lenguaje que viene del otro, pero que termina siendo introyectado a partir de la identificación y de otros mecanismos. Después se volverá para un análisis de la cultura y de cómo el símbolo y la capacidad de dar nombre a las cosas es parte fundamental de lo que nos hace humanos. Finalmente, pensamos la experiencia adolescente y sus particularidades en la relación con el nombre, el apodo y el proceso de renombramiento, que parecen servir a una tentativa de consistencia de sí, además de los referenciales heredados.

\section{Identificación y constitución de sí a partir del (o)Otro}

El concepto de identificación se presenta como uno de los más citados en el texto freudiano:

No hay en toda la teoría psicoanalítica, dominio más confuso, más exasperante para el lector que el de la teoría de la identificación. Al leerse la increíble proliferación de términos, supuestamente técni- 
cos que se ve aparecer en las publicaciones, se tiene la impresión de que la lista de las identificaciones no se detendrá nunca. (Taillandier, 1994, citado por Souza et al., pág.54).

O sea, se trata de un término ampliamente utilizado y, algunas veces, de forma poco clara. Frente a eso, nuestra intención no es la de rastrear completamente el concepto, sino la de localizar algunas de sus apariciones, relacionándolas con los temas aquí tratados.

En una rápida lectura sobre el texto freudiano podemos afirmar que el concepto de identificación aparece vinculado a los movimientos del sujeto en su relación edípica, es usado para pensar los destinos de la civilización en el mito del padre totémico, es referencia para pensar la dinámica de las relaciones de grupo, aparece como concepto fundamental para trabajar en la clínica del luto y de la melancolía y, aún, y no menos importante, en las reflexiones sobre la constitución de las instancias del Yo, Yo ideal, ideal del Yo y Superyó.

Freud (1974/1914), a partir del texto "Sobre narcisismo: una introducción", revela que el Yo solo se constituye en relación con otros. Esta tesis ya estaba implícita en la teoría del desamparo primordial presentada en "Proyecto para una psicología científica" (1974/1895), pero queda más clara posteriormente, cuando el autor comprende que la radicalidad del concepto de narcisismo está en el hecho de que este anuncia la prioridad ontológica del otro en relación al Yo. Sólo es posible construir una imagen de sí en y por la relación con el otro. En el texto de 1914, Freud argumenta que una unidad comparable al Yo no puede existir desde el comienzo, pero debe ser engendrada. $Y$ podemos pensar que los conceptos que denuncian la presencia del otro en la constitución del Yo son identificación e ideal del Yo. Para Freud, "el carácter del Yo, es una sedimentación de las investiduras de objeto resignadas, contiene la historia de estas elecciones de objeto" (Freud, 1974/1923, págs. 43-44), siendo el Yo "formado a partir de identificaciones que toman el lugar de investiduras abandonadas por el ello" (Freud, 1974/1923, pág. 64).

Sí, en el interior del Yo vive el Otro, entonces, el Yo es constituido en la relación con el Otro y esa alteridad habita el interior del Yo 
eternamente. Entonces, por ejemplo, al comprenderse el narcisismo se comprende que el cuerpo y el Yo se constituyen a partir del Otro, y la identificación será el concepto que vuelve efectiva la afirmación de que en el origen del Yo está el Otro. El Yo carga las marcas imborrables de la relación con el Otro. Según Freud (1974/1923), "puede ser que esa identificación sea la única condición para que el ello puede abandonar sus objetos" (pág. 43). Es decir, se trata de un proceso en el cual la catexia de objeto dirigida a los padres se transforma en identificación, con el fin de posibilitar la constitución del Yo como se puede ver en el siguiente apartado:

La identificación paterna preservará la relación de objeto con la madre que pertenecía al complejo positivo y, al mismo tiempo, sustituirá la relación de objeto con el padre, que pertenecía al complejo invertido; lo mismo será verdad, mutatis mutandis, en cuanto a la identificación materna. (pág. 48).

Ante esto podemos decir que la identificación participa del proceso de constitución psíquica, como es descrito en la teoría freudiana, que resultará en un Yo constituido a partir de la influencia del medio, pero que, simultáneamente, "no es el señor de su propia casa" (Freud, 1996/1917, pág. 153), ya que está subordinado a las presiones ejercidas por el inconsciente. Posteriormente, Lacan también dirá del proceso de transformación del infans (termino en latín usado para designar el animal humano al nacer) en un individuo humano $\mathrm{y}$, por eso, dividido psíquicamente. Nos interesa aquí, específicamente, sus reflexiones acerca del nombre propio, realizadas a partir de la noción de identificación en Freud en el seminario del mismo nombre (Lacan, 2003/1961-1962).

Ahora, ante la afirmación freudiana en el texto "Psicología de las masas y análisis del Yo" (Freud, 1974/1921) sobre la más temprana exteriorización de una ligazón afectiva con otra persona, Lacan formula la idea de trazo unario. Este se configura como una forma de inscripción primordial a la cual el infans se identifica y que, posteriormente, permitirá la escritura de su nombre propio. Siendo importante destacar que todo ese proceso no se hace sino teniendo como referencia el campo del otro, como esclarece Quinet (2012): 
Para todo ser humano, el otro es el tesoro de los significantes y, como tal, es previo al sujeto, es anterior al nacimiento. Antes de venir al mundo, ya le dan un nombre, un sexo, un equipo de futbol, una profesión; él ya nace en una determinada clase social con sus valores y preconceptos y en un país con su cultura y su lengua todo esto constituirá el Otro para él. (pág. 13).

En otras palabras, podemos decir que el bebé, en cuanto cuerpo biológico, nace dentro de determinada cultura y va siendo por ello subjetivado a través de las nominaciones que recibe de sus cuidadores, quienes buscan inscribirlo en diferentes narrativas, como la del lenguaje familiar. Es lo que significa el proceso de subjetivación para Lacan, la aprehensión de un cuerpo por el lenguaje. Como lo presenta Mariani (2014), se trata de una operación altamente compleja que humaniza al infans, aquel que aún no habla, insertándolo en lo simbólico y, por extensión, en la ley y en la cultura.

De esa operación se obtiene la división psíquica entre el Yo y el inconsciente, estructural e irreversible. El sujeto se presentará, entonces, como un operador que somos forzados a suponer una vez que reconocemos la incidencia del lenguaje en la experiencia humana y su convocación (Elia, 2010). En las palabras de Lacan (2008/1964), el inconsciente representa "la suma de los efectos del habla, sobre un sujeto, en ese nivel en que el sujeto se constituye por los efectos del significante" (pág. 126).

Pensando entonces sobre el lugar y la función del nombre propio, Souza et al. (2014) citan a Harari (2001) para indagar acerca de esa posición privilegiada entre sujeto y cultura:

Si preguntamos, una vez más, por nombre propio, surgen, como mínimo, estos interrogantes: ¿de dónde "salió"? ¿Pertenece al mundo interior de cada uno? ¿Le pertenece claramente? ¿Es aquello que mejor designa al sujeto? ¿Es el portador o porta voz de su singularidad? (pág. 58).

Es necesario, entre tanto, resaltar las diferencias entre dos modalidades de nominación: el nombre común y el nombre propio. Según Harari, citado por Souza et al. (2014): 
El nombre propio, como es destacado por Harari (2001), genera una identificación imaginaria en la medida en que sutura, nutre el desconocimiento propio de la constitución del YO (...). La alienación, propuesta por el nombre propio comporta un barniz narcisista incesante, derivado de lo que implica el "reconocerse" en sí mismo (...). (pág. 58).

O sea, el nombre propio carga en sí el peso de la identificación narcisista, que se constituye de forma alienada debido a la distorsión implícita en el proceso de constitución del yo desde el estadio del espejo, en el cual "la afirmación de la unidad del cuerpo propio (se da) en la identificación con la imagen especular" (Lacan, 2003/1938, pág. 73). Como apuntan Faustino y Falek (2014), se trata de una teorización lacaniana acerca de la ascensión de una unidad corporal con consecuencias directas en la constitución del Yo, pero dándose en un momento "anterior a la identificación característica del desenlace del complejo de Edipo” (pág. 474).

La problematización de la idea de la identificación invita, como consecuencia directa, a la reflexión sobre el asunto del Edipo. La identificación aparece en la trama edípica al lado del investimento libidinal o catexia libidinal. El niño ama la madre, o sea, produce una catexia de objeto en relación a la madre y una identificación con el padre. Pero ¿sería posible apenas un formato de identificación con el Edipo? El niño puede rehusarse ante la madre y transformar su catexia de objeto en una identificación regresiva, esto es, reflejarse en la madre para intentar construir una imagen de sí y, consecuentemente, despojarse de la identificación con el padre. La madre, como objeto en sí, es descartada, pero se mantiene en el inconsciente, a través de la identificación como un otro objeto incorporado y reproducido a través de la lógica del narcisismo.

La teoría freudiana argumenta que la identificación con la figura paterna es ambivalente, pues, en la prehistoria del Edipo y en la ubicación del mito totémico, esa identificación es representada por sus prototipos, que son la introyección y la incorporación oral. Freud (1974/1921) anuncia tres tipos de identificación. La primera, ya mencionada, se refiere a la incorporación del objeto; la segunda es denominada identificación regresiva, en la que la elección de objeto retro- 
cedió para una identificación metonímica; y, por último, se tiene la tercera identificación, que no resulta de una catexia de objeto directa y que se apunta como una identificación al síntoma.

De esa forma, considerándose la complejidad del concepto de identificación en el texto freudiano, es posible pensar sobre la importancia de la identificación para el adolescente construir su "vida verdadera". Souza et al. (2014), citando a Florence (1994), anuncian que la identificación es de la orden del romance inconsciente del sujeto, un modo de pensar inconsciente que modifica el Yo. Así, las primeras identificaciones que aparecen en el seno de la familia componen el cúmulo de identificaciones que posibilita la constitución del sujeto, que se deben renovar en la medida en que el sujeto se mueve en el tiempo y en los espacios. Así, un punto importante en el proceso de constitución del sujeto es la posibilidad de identificación y las nuevas modulaciones en relación al nombre propio.

\section{Nombramiento y constitución del hombre en cuanto ser cultural}

Podemos localizar la identificación, incluso en el pensamiento freudiano, acerca del surgimiento de la cultura a partir del mito del padre totémico. En "Tótem y tabú" (Freud, 1974/1913) la identificación entre los hermanos después del asesinato del padre es decisiva para la constitución de un nuevo lazo social. Podemos decir que es el primer indicio de la posibilidad de reconocimiento de la alteridad, o sea, del respeto de la diferencia, porque la hermandad constituida en la escena mítica del asesinato del padre totémico, se presenta como una forma de respeto. Los hermanos son iguales entre sí y tal identificación es reforzada por la presencia de un ideal común que es el padre muerto introyectado, tesis que reaparece en el texto "Psicología de las masas y análisis del Yo" (1974/1921).

O sea, podemos decir que la identificación se localiza tanto en la subjetivación de cada uno como en la constitución de lazos sociales entre los sujetos, siendo el lenguaje, o el proceso de dar nombre a las 
cosas y a las personas, parte esencial de esa dinámica. Incluso Lacan (2005/1974) unió esas dos dimensiones, individual y social, al referirse a la encarnación del verbo, elemento de la doctrina cristiana. En ella Lacan localiza el verbo como anterior al comienzo, una vez que él sería el instrumento de Dios en la creación del mundo. A Adán no le es dado el verbo, le es enseñado a nombrar las cosas 5 , pero él es encarnado posteriormente en la figura de Jesús, lo que Lacan relaciona posteriormente con la entrada del lenguaje y su consecuente división psíquica. Así, "si en el comienzo era el verbo" (Lacan, 2005/1974, pág. 74), a partir del momento en que este se hace carne, el hombre se transforma de manera radical y ya "no es más feliz de ninguna forma, no se parece en nada más con un perrito que mueve la cola, tampoco con un mono valiente que se masturba. (...). Está devastado por el verbo" (pág. 74).

Pero, así y todo, devastado por el verbo, aumentado en su condición simbólica, en palabras de Cassirer (1977/1944),

El círculo funcional del hombre no fue sólo cuantitativamente aumentado; padeció también un cambio cualitativo. El hombre, por así decir, descubrió un nuevo método para adaptarse al medio. Entre el sistema receptor y el sistema de reacción, que se encuentran en todas las especies animales, encontramos en el hombre un tercer enlace, que podemos describir como sistema simbólico. (pág. 49).

Cassirer revela que el principio del simbolismo es "ofrecer la palabra mágica que da acceso al mundo humano, es el jábrete sésamo! (1977/1944, pág. 65).

Moura (2006/2000) revela que el término "símbolo" ofrece la idea de separación y de reunión. Según la autora, el símbolo puede presentar fuerzas contrarias como la noche separada del día, el agua del fuego, la guerra de la paz, el hambre de la saciedad. Se tiene, en estos casos, la idea de separación; por otro lado, la conjugación de lo

5 En este texto, nombrar se utiliza en el mismo sentido de dar nombre, nominar. Sobre la discusión referida a la mejor traducción del término en la obra de Lacan, ver Leite (2006a). 
invisible con lo visible, por ejemplo, que sugiere la idea de unión. En las palabras de Mora, "el símbolo, con ese carácter polar, se impone, ante todo como apertura y promesa con el principio de movimiento y de orientación, como un sentido oculto que el hombre trae consigo" (pág. 78). Así, podemos concluir que la posibilidad de nombrar nos hace humanos, observándose que la acción de nominación permite, incluso, zigzaguear lo indecible, la muerte, el límite, la falta. Pero, ¿cómo cada sujeto puede acceder a este mundo de la nominación?, ¿será posible acceder al mundo de la nominación de forma insistente?, ¿es suficiente apenas conocer las palabras?, ¿existe una operación central que organiza esta entrada en el mundo de la vida?

El hombre no vive solamente la realidad y sí una nueva dimensión de realidad (Cassirer, 1977/1944, pág. 49). O sea, el hombre no vive en un universo meramente físico y natural, hay también un universo simbólico donde el lenguaje, el mito, el arte, la religión y otros constituyen los hilos que "tejen la red simbólica, la trama enmarañada de la experiencia humana (pág. 50). No se cuestiona aquí la idea de que los animales establecen formas de comunicación, ni que siempre reaccionan de manera directa a los estímulos, pudiéndose citar el célebre experimento pavloviano que hacía salivar a los perros con el sonido de una campana como un ejemplo de reacción indirecta. En el caso de la comunicación, según Cassirer (1977/1944, pág. 57), la diferencia entre el lenguaje animal y lenguaje humano es la proporcionalidad del último: el lenguaje animal se restringe a lo emocional, y el humano presenta una intención. Cassirer, en la defensa de la tesis de que el hombre es un ser simbólico, retoma la narración de la profesora Sullivan sobre Helen Keller: "necesito escribirle una línea hoy temprano porque algo muy importante sucedió. Helen dio el segundo gran paso en su educación. Aprendió que todo tiene un nombre y que el alfabeto manual es la clave" (Sullivan citado en Cassirer, 1977/1944, pág. 63, cursiva añadida).

Así, la acción de nombrar o nominar es específicamente humana. Podemos afirmar que la idea de nominación, como estructuradora del sujeto, encuentra fundamentación en la tesis de Cassirer (1971/1923, 1977/1944), que propone que "en lugar de definir al 
hombre como un animal rationale deberíamos definirlo como animal symbolicum" (1977/1944, pág. 51). El autor discute sobre las diferentes definiciones del humano a lo largo de la historia de la filosofía presentando posiciones desde los presocráticos hasta la filosofía moderna. En esta, es interesante destacar la posición de Pascal, que afirma: "el hombre no es ángel ni animal" (1983/1670, pág. 125). El filósofo defiende la idea de la desapropiación del hombre en relación a sí mismo, mirada que se sitúa entre lo divino, representante del orden cultural, y lo animalesco, que se refiere a la naturaleza, pero no es término medio, equilibrio entre estos dos extremos. En el hiato entre esas dos instancias (cultura y naturaleza), podemos localizar la importancia fundamental del símbolo. Según Cassirer, el hombre produce una nueva manera de relacionarse con la naturaleza incluso creando nuevas formas de realidad.

Históricamente, el nombre propio es patronímico, o sea, "es un nombre recibido por medio de genealogía, un nombre transmitido, digamos que él viene automáticamente del Otro" (Soler, 2009, pág. 172). Por medio del nombre propio es posible inscribir al individuo en el seno de un linaje con sus antecedentes, bienes y fantasmas, revelando, pues, que la identidad es siempre múltiple. Soler afirma que: "indistintamente del nombre común cuyo referente es, generalmente, una clase de cosas, se espera del patronímico la indexación de una, y apenas una, existencia independiente de cualquier cualidad a no ser la descendencia" (pág. 172).

Entre tanto, es importante apuntar la diferencia entre el apellido y el nombre, puesto que, según Soler (2009), el nombre "no es transmitido automáticamente, ya que inscribe una elección" (pág. 179). Así, el nombre propio de un sujeto posee la historia del linaje familiar a través del apellido, herencia que perpetúa la idea de patronímico, y el nombre, espacio de inscripción y transmisión de deseos inconscientes. Para Tesone (2009), el nombre es como "una segunda piel, envuelve al niño, le sirve de límite entre su cuerpo y el cuerpo del otro" (pág. 149). Podemos decir que el apellido ofrece la transmisión de la herencia cultural, mientras que en el nombre se entrecruzan los sueños de los padres en relación con los hijos (Tesone, 2009). 


\section{Nombres, renombramientos y apodos: la experiencia adolescente entre el Yo y el otro}

Lewis Carroll, en su fantástica obra, Alicia al otro lado del espejo, nos presenta un elemento para reflexionar sobre las posibles funciones de un nombre propio, en un diálogo entre Alicia y un personaje que tiene la forma de huevo. Veamos el pasaje:

"No se quede ahí hablando solita" dice Humpty Dumpty, mirando hacia Alicia por primera vez. "Dime tu nombre y lo que haces"

Mi nombre es Alicia, pero...

Es un nombre bastante estúpido, interrumpió Humpty Dumpty, impaciente, "¿qué quiere decir?"

¿Un nombre tiene que significar alguna cosa? Preguntó Alicia llena de dudas.

"Claro que tiene", dice Humpty Dumpty, con una carcajada. Mi nombre significa la forma que tengo $\mathrm{y}$, dicho sea de paso, es una forma bien elegante. Con un nombre como el tuyo, casi que puede tener cualquier forma. (Carroll, 2013/1865).

Humpty Dumpty, es un personaje de cuentos infantiles ingleses cuya cabeza tiene forma de huevo. Según Torres (2010, 12 de junio), el término utilizado para nombrar al personaje, Humpty Dumpty, es una expresión usada en Inglaterra para ofender a alguien que es "bajito y gordito". A partir de esas informaciones, dos cosas emergen en la discusión: el significado de un nombre propio y la posibilidad de los apodos de representar formas satíricas para nombrar a un sujeto, tomando la parte por el todo. Podemos pensar que la creación de apodos es una forma de matar al otro y de reducirlo a un punto metonímico, negar al sujeto en su diferencia, reducirlo a una denominación jocosa.

Algunas investigaciones que buscan entender el problema del bullying apuntan al uso de apodos como una forma de agresión verbal, un vehículo para hacerlo efectivo. En una investigación que 
tenía como objetivo mapear las reacciones de adolescentes al frente de una experiencia de bullying, Oliveira e Antônio (2006) revelan que los adolescentes presentan constreñimientos y tristezas al momento en que se identifican con apodos impuestos por los otros jóvenes. Los apodos resaltan alguna característica física o psicológica que expone y ridiculiza al sujeto apodado. Parece pertinente enfatizar que artículos científicos producidos en diferentes campos, como medicina (Scutti et al., 2014), enfermería (Oliveira \& Antônio, 2006), psicología y educación (Bandeira \& Schutz, 2010) y ciencias sociales (BolzanBerlese et al., 2017), trabajan el tema del bullying y las articulaciones posibles entre este acto y la utilización de apodos.

Así, podemos decir que el proceso de bullying envuelve cierta cuota de desprecio direccionado al otro. Como lo presentó Freud (1974/1921), "en las antipatías y aversiones sin disfraz que las personas sienten por extraños con los que tienen que tratar, podemos identificar la expresión de amor a sí mismo del narcisismo" (pág. 44). En otras palabras, podemos localizar en el narcisismo una forma de direccionamiento de la agresividad hacia el otro, siendo el amor la fuerza capaz de frenarlo y, por ello, denominado por Freud (1974/1921) como "un factor de cultura" (pág. 44). Por otro lado, cuando la identificación con el objeto se vuelve maciza, como en el caso de la melancolía, la sombra del objeto puede producir un eclipse en el Yo.

Entonces, la identificación se hace presente en el campo de las relaciones objetuales, incluso en el momento de la pérdida de objeto con sus particularidades, como lo estableció Freud (1974/1917).
Si el amor por el objeto -ese amor que no puede resignarse a la par que el objeto mismo es resignado- se refugia en la identificación narcisista, el odio se ensaña con ese objeto sustitutivo insultándolo, denigrándolo, haciéndolo sufrir y ganando en este sufrimiento una satisfacción sádica. (pág. 284).

Esa importante discusión sobre la identificación que aparece en el texto "Luto e melancolia" (1974/1917), es pensada a partir de la idea de objeto perdido, "objeto muerto", que es incorporado al Yo, repre- 
sentando la idea de identificación regresiva e introyección. La posibilidad de la división en el Yo y la condición de autocrítica que son derivadas del proceso de la melancolía reubican en el texto freudiano la discusión sobre la instancia del ideal del Yo, asociada a la conciencia moral, tema que aparecerá, posteriormente, en la figura del súper Yo como heredero del complejo de Edipo; y la idea de que el Yo es el resultado de las identificaciones perdidas, anuncia la posibilidad de defender la hipótesis acerca de la identificación como un importante mecanismo psicológico de la constitución del psiquismo. Podemos afirmar que en la constitución del Yo está presente la historia de las elecciones frustradas de objeto y, así, la presencia del otro es irreductible y traumatizante. El otro no puede ser consumido, deja a través de la identificación, las marcas de su presencia en la estructuración del Yo.

El apodo, en ese sentido, también integra la historia de cada individuo escrita a partir de las marcas dejadas por las relaciones con el otro. No podemos olvidar que los apodos también pueden aparecer como forma de enaltecimiento de una cualidad de sujeto. Un ejemplo de eso es el caso del personaje de Guimaraes Rosa en el Grande Sertão: Veredas (1986/1956): Riobaldo, también llamado de Tatarana o UrutuBlanco. El apodo de Tatarana se refiere a la idea que Riobaldo se parece a un lagarto de fuego; y Urutu-Blanco sugiere que el personaje es como una serpiente peligrosa o traicionera que da el salto al enemigo. El apodo de Tatarana, por tanto, se refiere a un contexto particular y proviene de los otros, pudiendo presentar diferentes funciones como enaltecimiento, complicidad, crítica o agresión verbal. El punto central parece ser que el apodo, elige un punto, un trazo del sujeto como definidor del todo.

Hay, por otro lado, el fenómeno del renombramiento, que parece presentar otros elementos. Para Soler (2009), "podemos encontrar un indicio simple en el hecho de que determinados sujetos consiguen cambiar de nombre por medio de sus obras" (2009, pág. 172). El renombramiento parece implicar un movimiento de reinvención de sí, un nacer de sí mismo con el nuevo nombramiento. De esa forma, es posible argumentar que como la adolescencia se caracteriza por una ruptura con lo "antiguo", pensar en nuevas inscripciones de nom- 
bramiento tal vez sea una acción común en este momento, como una forma de experimentación de sí.

Según Le Breton (2009), la juventud es un tiempo de experimentación y libertad, lo que abre espacio para la aparición de conductas de riesgo, algunas como trasgresiones mínimas, como bajarse del bus sin pagar, otras que pueden enmarcarse como acto infractor y, aún, otras que ponen en riesgo la vida. De acuerdo con este autor, las conductas de riesgo comunes en la adolescencia se presentan como restauración narcisista. En la concepción del autor, el peligro y desafío constituyentes de la conducta de riesgo posibilitan la construcción de una "imagen mejor de sí mismo, construir una imagen de sí, expulsar lo más lejos posible el miedo de la insignificancia" (Le Breton, 2009, pág. 41). Podemos preguntar, entonces, si la creación de nuevos nombres no respondería a este deseo de restauración narcisista de sí: ¿sería el renombramiento el deseo de definición de un punto identificador, una unidad que englobe el ser de sí mismo?, ¿o una forma de quebrar una unidad imaginaria del nombre paterno? Se considera que un movimiento no inviabiliza al otro.

Es importante recordar, aún, que para que un nuevo nombre se inscriba y consolide es necesario que se acoja y reconozca por el otro. Volviendo a Soler (2009), algunos sujetos logran una recreación de sí a través de un renombramiento en el campo de las artes. Ejemplo de aquello es el de un adolescente de una agrupación juvenil bautizado como Octavio (Bolaños, 2017), que se presenta con el nombre artístico de Tres, un rapero que se constituye en otra persona diferente de Octavio; esta nueva identidad permite a Tres un nuevo acceso al mundo. El joven revela que encontró sus raíces y ahora "lo que Yo soy, es lo que Yo siempre quise ser" (Bolaños, 2017, pág. 115). Aún más, el autor cita a José Jaime que se presenta como Joyjo y, con este nuevo nombre, transforma su vida y permite la comunicación, la salida del anonimato. Se puede deducir que las nuevas nominaciones son atravesadas por deseos inconscientes, que los nuevos nombres poseen las marcas, los surcos de las historias y traumas de cada sujeto; pero lo que parece nuevo es el deseo del sujeto por una nueva inscripción sin deshacerse de la antigua, ya que en el renombramiento el sujeto participa activamente del cambio -presupone el asentimiento del sujeto-, 
a diferencia de lo que pasa con el apodo que es, la mayoría de veces, una imposición del Otro.

Siguiendo a Tesone (2009), quien nos revela que el "nombre posee una fuerza significante, es el punto de articulación entre el ante texto (mito familiar) y el texto (el sujeto)" (pág. 145), cabe preguntar si el renombramiento posibilita una nueva articulación con el mito familiar y con su mito individual. En ese sentido, creemos que es importante diferenciar entre renombramiento y apodos.

Bolaños (2017) consideró un aspecto interesante para la reflexión: algunos adolescentes presentaban risas luego de mencionar su nuevo nombre, lo que generó una duda en el autor sobre cuál sería la fuente de placer para esa risa. Los casos citados son Tirador y Virus. Tirador es grafitero y rapero, vive con padres y hermanos, y mostró gratitud para con su familia, aunque se definiera como:

la "oveja negra" de la familia y un frustrado en varios campos. "Yo soy un skater frustrado, roquero frustrado y un jugador de fútbol frustrado", pero también se refiere a ser "creativo", "autoconsciente", "buscador de la libertad" y "un poeta ambulante". (Bolaños, 2017, pág. 109).

La denominación de este adolescente con un apodo se vincula con una propaganda de la televisión y un juego virtual. Nos parece interesante mencionar que el apodo Tirador podría estar relacionado con la idea de francotirador; existe una película inglesa de Clint Eastwood (2014) que presenta datos biográficos de un importante y exitoso francotirador norte- americano. Con ello, es importante preguntar, ¿en qué punto cómico este tirador se puede relacionar con el francotirador americano?

Por su parte, Virus es el único hombre en su seno familiar. Desde que el padre abandonó a la familia, luego de su nacimiento, él vive con la madre y tres hermanas. ¿Sería el apodo "Virus" la respuesta a un posible deseo materno de que el niño ocupase un lugar fuerte en su familia? Así, ¿sería Virus una manera de renombrar que opera una acción de acoger y negar un posible deseo materno? Freud 
(1974/1927), en el texto "O humor" hace una articulación de esta forma cómica con la Verleugnung, con el desmentido. Es posible que la risa de virus con el nuevo nombre denuncie la relación de este apodo con el inconsciente.

Bolaños (2017) ofrece una excelente interpretación, indicándonos que en ambos casos la risa funciona como fuga. El nuevo nombre evita, pero denuncia, la tensión con la herencia de la tradición, sea de la familia, de la escuela o del Estado, por medio de la confrontación con la policía: "así, con sarcasmo y cinismo Tirador intenta mostrar la castración de policías y educadores cubriéndose como buen francotirador; o sea, escondiendo su propia castración" (pág. 152).

Freud (1976/1927) nos presenta una nueva posibilidad de pensarse la convocatoria para una Verleugnung, o un desmentido. En su estudio sobre la dinámica del humor, Freud introduce la idea de que la acción humorística representa una tentativa del psiquismo de librarse de un afecto negativo producido por una situación específica. Como ejemplo cita el comentario de un criminal que al ser llevado a la horca afirma: "comenzamos muy bien la semana" (pág. 189). En la interpretación freudiana, en el humor tendríamos "un triunfo del narcisismo en la afirmación victoriosa de la invulnerabilidad del Yo" (pág. 190). El Yo desmiente la realidad sin rechazarla totalmente y, aún, toma algún placer de la escena.

Así, el humor presenta un tipo de superioridad del Yo, pero es importante resaltar una superioridad rebelde. Como revela Freud, no apenas "un triunfo del Yo es también del principio del placer" (pág. 191). Retomando el comentario del criminal, Freud argumenta que él podría haber dicho: "eso no me preocupa. Qué importancia tiene, al final de cuentas, que un sujeto como Yo sea ahorcado" (pág. 190). Este comentario presenta el triunfo del Yo, pero no la ganancia de placer.

De esa forma, la actitud humorística consiste en ofrecer para la persona el rechazo del sufrimiento, dando énfasis a la invencibilidad del Yo en relación al mundo real, y sustenta victoriosamente el principio de placer (pág. 191). De igual forma, según Freud, las dos características de la acción humorística -el rechazo de las reivindicaciones 
de la realidad y la concreción del principio del placer- aproximan el humor a los procesos regresivos o de reacción que tan ampliamente atraen la atención en la psicopatología (pág. 190). Podemos pensar, entonces, que en el caso de Tirador y de Virus, el renombramiento ofrece un punto de unión que conecta con un desmentido, una defensa con relación a lo tradicional.

Así, vemos cómo el nombre propio y su modificación por parte del adolescente funcionan como un indicativo de la identificación en el lazo social, una forma de representar y designar al sujeto. Cada nombre propio es singular, ya que se relaciona con la "diferencia única y primordial en cada sujeto" (Mariani, 2014, pág. 140); pero, ¿no sería el renombramiento una herramienta en la tentativa de ascenso del adolescente, independiente de aquello que hereda del otro mientras posee el don de nombrar, incluso a sí mismo?

\section{Consideraciones finales}

Para concluir, citaremos a Leite (2006b):

El nombre propio, no puede ser tratado como una simple etiqueta, pues, al configurarse en el registro de la identificación, acción fundante para el ser humano, el nombre se implica en la localización del sujeto, en la interpelación, tomando otras direcciones en los estudios del lenguaje. (pág. 299).

Considerando que el nombre propio se configura en un registro de identificación, nos parece importante diferenciar la acción de renombrar, de la creación de apodos. La sustitución del nombre por un nuevo nombre revela el deseo del sujeto de inscribirse en la relación con otro de una nueva forma. A su vez, los apodos pueden representar la marca de crueldad del otro, o una exaltación de una característica, derivando, en todo caso, del otro e inscribiéndose en el circuito particular de un grupo. Con la sustitución del nombre, el sujeto ansía un nuevo reconocimiento y, a veces, un nuevo nacimiento, aunque el nombre contenga marcas de las historias ya vividas. 


\section{Referencias}

Eastwood, C. (2014). American Sniper [película]. Warner Bros.

Bandeira,C.deM.\&Hutz,C.S.(2010).Asimplicaçõesdobullyingnaauto-estima deadolescentes.Psicol.Esc. Educ.(Impr.), 14(1),131-138.http:/ / www.scielo.br/scielo.php?script=sci_arttext\&pid=S1413-85572010000100014\&ln $\mathrm{g}=\mathrm{pt \& nrm}=$ iso.

Bolaños, D. F. (2017). "Respiramos el mismo aire; pero somos diferentes". Constitución de subjetividad en adolescentes integrantes de agrupaciones juveniles de ciudad en Mar del Plata (Argentina) y Cali (Colombia) [tesis de doctorado, Universidad Federal de Minas Gerais, Brasil]. Repositorio UFMG. https://repositorio.ufmg.br/bitstream/1843/BUOS-AQRNGJ/1/ bola_os_d._f._constituci_n_de_subjetividad_en_adolescentes._ppg fae_ufmg._completo_com_numeraca.pdf.

Bolzan-Berlese, D., Roese-Sanfelice, G., Bolzan Berlese, D. \& Sidegum, Renner, J. (2017). Bullying e violência social: vivência de adolescentes obesos. Revista Latinoamericana de Ciencias Sociales, Niñez y Juventud, 15(1), 491-503. http:/ / www.scielo.org.co/pdf/rlcs/v15n1/v15n1a32.pdf.

Carroll, L. (2013/1865). Alice: edição comentada e ilustrada. Aventuras de Alice no País das Maravilhas \& Através do espelho. Zahar.

Cassirer, E. (1971/1923). Filosofia das formas simbólicas I. A Linguagem. Fondo de Cultura Económica.

Cassirer, E. (1977/1944). Antropologia filosófica. Ed. Mestre Jou.

Elia, L. (2010). O conceito de sujeito. Zahar.

Faustino, D. y Falek, J. (2014). A originalidade e a origem do estádio do espelho em Lacan. Estilos da Clínica, 19(3), 465-481. http:/ / pepsic.bvsalud. org/pdf/estic/v19n3/a06v19n3.pdf.

Freud, S. (1974/1895). Projeto para uma psicologia científica. En Freud, S. Edição standard brasileira das obras psicológicas completas de Sigmund Freud (Jayme Salomão, trad., vol. I, págs. 385-529). Imago.

Freud, S. (1974/1913). Totem e tabu. En Freud, S. Edição standard brasileira das obras psicológicas completas de Sigmund Freud (Jayme Salomão, trad., vol. XIII, págs. 11-125). Imago.

Freud, S. (1974/1914). Sobre o narcisismo: uma introdução. En Freud, S. Edição standard brasileira das obras psicológicas completas de Sigmund Freud. (Jayme Salomão, trad., vol. XIV, págs. 83-119). Imago.

Freud, S. (1974/1917). Luto e melancolia. En Freud, S. Edição standard brasileira das obras psicológicas completas de Sigmund Freud (Jayme Salomão, trad., vol. XIV, págs. 249-263). Imago. 
Freud, S. (1974/1921). Psicologia de grupo e análise do eu. En Freud, S. Edição standard brasileira das obras psicológicas completas de Sigmund Freud (Jayme Salomão, trad., vol. XVIII, págs. 89-179). Imago.

Freud, S. (1974/1923). O eu e o Isso. En Freud, S. Edição standard brasileira das obras psicológicas completas de Sigmund Freud (Jayme Salomão, trad., vol. XIX, págs. 11-83). Imago.

Freud, S. (1974/1927). O humor. En Freud, S. Edição standard brasileira das obras psicológicas completas de Sigmund Freud (Jayme Salomão, trad., vol. XXI, págs. 98-103). Imago.

Freud, S. (1996/1917). Uma dificuldade no caminho da psicanálise. En Freud, S. Edição standard brasileira das obras psicológicas completas de Sigmund Freud (Jayme Salomão e Orizon Carneiro Muniz, trads., vol. XVII, págs. 84-90). Imago.

Lacadée, PÁG. (2007). A passagem ao ato nos adolescentes. Revista Eletrônica do Núcleo Sephora, 2(4). http://www.isepol.com/asephallus/numero_04/asephallus04.pdf

Lacan, J. (2003/1938). Os complexos familiares na formação do indivíduo. En Outros Escritos (págs. 29-90). Jorge Zahar.

Lacan, J. (2003/1961-1962). A identificação: Seminário. Centro de Estudos Freudianos do Recife.

Lacan, J. (2005/1974). O triunfo da religião: Precedido de discurso aos católicos. Zahar.

Lacan, J. (2008/1964). O Seminário, Livro 11: Os quatro conceitos fundamentais da psicanálise. Zahar.

29-90Le Breton. (2009). Condutas de risco: dos jogos de morte ao jogo de viver. Autores Associados.

Leite, C. A. (2006a). N'homear: os Nomes-do-Pai e a escrita. En II Congresso Internacional de Psicopatologia Fundamental, 2. FAPESPÁG. http:/ / www. psicopatologiafundamental.org.br/uploads/files/ii_congresso_internacional/temas_livres/nhomear.pdf.

Leite, C. A. (2006b). O nome próprio e sua relação com o inconsciente. Sínteses. Revista dos cursos de Pós-Graduação, 11, 295-304. http:/ / revistas.iel. unicamp.br/index.php/sinteses/article/view/190

Mariani, B. (2014). Nome próprio e constituição do sujeito. Letras, 24(48), 131-141. Doi: https:// doi.org/10.5902/2176148514428.

Moura, M. R. (2000/2006). O simbólico em Cassirer. Ideação, 5, 75-85. http:/ / gepai.yolasite.com/resources/O\%20SIMB \% C3\% 93LICO \% 20EM\% 20 CASSIRER.pdf.

Oliveira, A. S. \& Antônio, P. da Silva. (2006). Sentimentos do adolescente relacionados ao fenômeno bullying: possibilidades para a assistência de 
enfermagem nesse contexto. Revista Eletrônica de Enfermagem, 8(1), 30-41. https://revistas.ufg.br/fen/article/view/946.

Pascal, B. (1983/1670). Pensamentos. Abril Cultural.

Quinet, A. (2012). Os Outros em Lacan. Zahar.

Rosa, J. G. (1986/1956). Grande sertão: Veredas. Nova Fronteira.

Rosa, M. D. A. (2004). Pesquisa psicanalítica dos fenômenos sociais e políticos: metodologia e fundamentação teórica. Revista Mal-Estar e Subjetividade, 4(2), 329-348. http:/ / pepsic.bvsalud.org/scielo.php?script=sci_art text\&pid $=$ S1518-61482004000200008.

Scutti, C. S., Seo, G. Y., Amadeu, R. S. \& Sampaio, R. (2014). O enfrentamento do adolescente obeso: a insatisfação com a imagem corporal e o bullying. Revista da Faculdade de Ciências Médicas de Sorocaba, 16(3), 130-133. http:/ / revistas.pucspág.br/index.php/RFCMS/article/view/15188.

Soler, C. (2009). Os nomes da identidade. Trivium: Estudos Interdisciplinares Psicanálise e Cultura, 1(1), 171-177.

Souza, L. B., Danziato, L. \& Barreira, J. (2014). Das relações entre identificação enomeação: o sujeito e o significante. Rev. Subj., 14(1),53-61. http:/ / pepsic.bvsalud.org/scielo.php?script=sci_arttext\&pid=S2359-07692014000100006\&ln $\mathrm{g}=\mathrm{pt \& n}$ rm=iso.

Tesone, J. E. (2009). Inscrições transgeracionais no nome próprio. J. psicanal, 42(76),137-157.http:// pepsic.bvsalud.org/scielo.php?script=sci_art text\&pid=S0103-58352009000100010\&lng=pt\&nrm=iso.

Torres, F. (2010, 12 de junio). Humpty Dumpty. Folha de S. Paulo. http:// www1.folha.uol.com.br/fsp/poder/po1206201016.htm. 